\title{
Possíveis interações entre o desenvolvimento sustentável e a logística de combustíveis
}

\author{
Mauricio Henrique Benedetti Mackenzie; UFSCar \\ Patricia Lima Mackenzie \\ Luana Melatto Mackenzie \\ Marcos Silva Mackenzie
}

\section{RESUMO}

Este artigo, de caráter exploratório, procurou compreender de que maneira as operações logísticas podem contribuir para um desenvolvimento sustentável, dentro de um contexto em que as organizações, juntamente com o poder público e a sociedade, assumem o importante papel de agentes de uma mudança conceitual da maneira de conduzir os negócios. Realizou-se um estudo em uma grande distribuidora de combustíveis da região metropolitana de São Paulo, onde foram entrevistados gerentes e encarregados envolvidos com os processos operacionais, segurança do trabalho e recursos humanos. Os dados coletados foram submetidos a análise de conteúdo e revelaram uma forte relação das atividades logísticas com o desenvolvimento sustentável. Observou-se ainda que uma visão estratégica que busque a sustentabilidade dos negócios necessita considerar, além dos aspectos econômicos, dentre os quais se encontram os processos operacionais, aspectos sociais e ambientais, o que inclui o envolvimento da organização com seus diversos stakeholders.

\section{Possible interactions between the sustainable development and the fuel logistics}

\begin{abstract}
This exploratory study tried to understand the influence of the operations logistics for the firm's sustainable development, assuming a context that the firms work together with the public authorities and the society as agents of change of management. The study took place in the major fuel dealer in the Metropolitan Area of São Paulo. The managers and supervisors involved with the operational processes, safety of the work and human resources were interviewed. The content analysis of the interviews revealed a strong relationship of the logistics activities with the sustainable development of this fuel dealer. It was also observed that, besides the economical aspects and the operational processes, a strategic vision needs to consider the social and environmental aspects, which includes the involvement of the organization with their several stakeholders.
\end{abstract}

KEY WORDS

Sustainable development, logistics, fuel, exploratory research. 


\section{INTRODUÇÃO}

A frequente preocupação em manter a competitividade dos negócios, por vezes, leva gestores a deixarem em segundo plano a atenção para o desenvolvimento sustentável, tratando esses dois objetivos como excludentes em seus planejamentos estratégicos. A mudança da visão que indicava como objetivo da organização apenas a obtenção de lucro para seus acionistas, os shareholders, para uma visão que estende estes objetivos a outros stakeholders da organização, trouxe à luz a preocupação com a manutenção dos recursos necessários ao funcionamento dos negócios. Esta é uma consequência do maior questionamento que as pessoas estão fazendo sobre o papel das organizações dentro da sociedade.

Argandoña (1998) aponta como principal obrigação dos stakeholders a contribuição para que a empresa atinja suas metas, o que, em sua visão, significa contribuir para o bem comum. A contribuição das organizações para a construção do bem comum pode ser em maior ou menor nível, porém todas têm seu papel para o desenvolvimento sustentável, não importando o setor da economia em que operem. Um exemplo são as empresas de manufatura que buscam processos de produção mais "limpos" e matérias-primas alternativas, além de darem um destino ecologicamente correto aos seus descartes de resíduos. São processos operacionais que não são mais desenvolvidos apenas a partir da idéia do ganho em produtividade e redução de custos, mas também considerando a preservação dos recursos naturais, suas implicações sociais e sem perder de vista os resultados econômicos.
Neste contexto, este artigo teve como objetivo central estudar as operações logísticas de uma distribuidora de combustíveis e sua interação com a questão do desenvolvimento sustentável. Para o alcance de seu objetivo geral, este estudo teve dois objetivos específicos: a) identificar atividades operacionais da logística de combustíveis que interferem no desenvolvimento sustentável; b) compreender as relações da organização com seus stakeholders no âmbito econômico, social e ambiental.

\section{REFERENCIAL TEÓRICO}

\subsection{Logística}

A logística é um assunto que ganhou destaque no desenvolvimento estratégico das organizações em busca de uma vantagem competitiva a partir da década de 1990, com a abertura dos mercados em consequência do processo de globalização. Fleury et al. (2000) veem a logística como um "verdadeiro paradoxo", uma vez que se trata ao mesmo tempo de uma das atividades econômicas mais antigas e de um dos conceitos mais modernos.

O que faz da logística um conceito moderno é um conjunto de mudanças econômicas e tecnológicas. As econômicas exigem da atividade logística uma maior especialização e cobranças competitivas. Já as mudanças tecnológicas possibilitam à logística gerenciar estoques, administrar o manuseio e a armazenagem de forma eficaz e eficiente (FLEURY et al., 2000). Essas mudanças vêm transformando a visão da logística dentro das empresas, que passou a ser encarada não como uma simples atividade operacional, um centro de custos, mas como ferramenta gerencial para a administração estratégica, visando à obtenção de vantagem competitiva para a organização (FLEURY et al., 2000; BALLOU, 2006).

O mesmo desenvolvimento de processos operacionais socialmente responsáveis começa a ser inserido em outras organizações além das de produção, como as empresas de logística, as quais são responsáveis por manipularem e transferirem os produtos de um lugar para outro. Estas organizações contribuem para um desenvolvimento sustentável ao oferecer segurança aos seus colaboradores, não eliminarem resíduos em locais que não sejam apropriados para este fim, não exporem a sociedade a riscos devido a operações negligentes e que desatendam as normas de segurança, dentre outras ações neste sentido. Se os produtos movimentados pela empresa forem perigosos, estes cuidados merecerão atenção especial.
Contudo, observam-se gargalos estratégicos e operacionais que, muitas vezes, são desconsiderados no planejamento e nas ações dentro da cadeia de suprimentos. À medida que aumentam os níveis de fornecedores, distribuidores, diversidade de operações e produtos, considerando-se o ponto de origem até chegar ao consumidor final, a complexidade dessa gestão aumenta drasticamente (LAMBERT; COOPER, 2000; DORNIER, et al. 2000).

A função logística caracteriza-se por um amplo escopo que inclui o planejamento, a alocação e o controle de insumos e produtos de uma organização. Neste conceito operacional há também o gerenciamento do processo de distribuição 
física, de estocagem e movimentação dentro da organização ou entre organizações (CHRISTOPHER, 1977).

Um conceito de logística bastante difundido e utilizado na era da globalização é o adotado pelo Council of Logistics Management:

"A logística é a parte do gerenciamento da cadeia de suprimentos que planeja, implementa e controla a eficiência e a eficácia do fluxo e armazenamento de bens, serviços e informação relacionada entre o local de origem e o ponto de consumo a fim de satisfazer as exigências dos clientes." (COUNCIL OF LOGISTICS MANAGEMENT, 1998).

Como apontado por Lambert et al. (1998) o conceito do Council of Logistics Management trata da administração da logística, isto é, inclui serviço ao cliente, tráfego e meios de transporte, armazenagem e estocagem, escolha do local para fábrica e armazéns, controle de inventário, processamento de pedidos, comunicações de distribuição, compras, movimentação de materiais, serviço de fornecimento de peças, remoção do lixo industrial, embalagem, devolução de mercadorias e previsão de volume de pedidos.

Uma visão ampliada dos conceitos de distribuição física e logística, integrando as atividades dessas áreas, fez com que surgisse um novo termo: o Supply Chain Management (SCM). Segundo Ballou (2006), esse termo passou a ser utilizado como uma visão ampliada dos conceitos de distribuição. Entra a ideia de coordenação ao longo do canal de distribuição, que inclui as compras, produção e distribuição física, a qual é a base das práticas do SCM de hoje. Portanto, é importante pontuar que os conceitos de logística e SCM devem ser distintos, ou seja, a logística é uma parte do SCM. Mais especificamente, a administração da logística é uma parte do SCM que planeja, implementa e controla a eficiência do fluxo em ambas as direções do fornecimento de produtos, serviços e informações relacionadas entre o ponto de origem e o ponto de consumo para atender às necessidades dos consumidores (BALLOU, 2006). Para Lambert e Cooper (2000), o SCM é a integração dos principais processos de negócios a partir do usuário final até os primeiros fornecedores que proveem produtos, serviços e informações que adicionam valor aos consumidores e outros stakeholders. Na concepção do SCM, o fluxo dos materiais é puxado, baseado nas necessidades dos consumidores.

O SCM integra as atividades logísticas de empresas que trocam entre elas materiais e informações ao longo de um canal de distribuição, ou seja, atividades de outbound para um e inbound para outro. Portanto, o SCM é visto como o gerenciamento do fluxo de produtos entre várias empresas, enquanto a logística é vista como o gerenciamento das ati- vidades pertencentes ao fluxo de produtos dentro de uma empresa.

Ao fazer uma revisão da literatura a respeito do SCM, Tan (2000) observou o predomínio de dois caminhos distintos: (a) compras e suprimento; e (b) transporte e funções logísticas. Na perspectiva de compras e suprimentos da literatura, o foco está nas funções de compra e gestão de suprimentos de compradores industriais, enquanto na perspectiva de transporte e funções logísticas engloba-se o transporte e as funções de distribuição física de atacadistas e varejistas. A ideia é integrar esses dois caminhos e unificar o SCM em uma comum e aceitável terminologia que envolve todas as atividades de valor ao longo da cadeia.

Quando as duas perspectivas a respeito do SCM são integradas, aparece a importância de incorporar a gestão da cadeia de suprimentos em todos os processos de planejamento dos negócios (TAN, 2000). O objetivo da integração da estratégia ao longo da cadeia é criar processos de manufatura e funções logísticas alinhados por toda a cadeia de suprimentos como uma efetiva arma competitiva, que seja difícil de ser superada ou duplicada pela concorrência.

\subsection{0 s produtos perigosos}

A logística tratada nos ambientes de empresas que trabalham com combustíveis implica em compreender o manuseio, o transporte e a armazenagem de produtos perigosos. Aqui cabe ressaltar o significado de produtos perigosos, os quais são considerados aqueles que “... por suas propriedades físicas ou químicas, oferecem algum risco ao ser humano, ao meio ambiente ou ao transporte" (VIANA, 2000, p. 368).

A Agência Nacional de Transportes Terrestres (ANTT) acrescenta que são considerados produtos perigosos, também, as substâncias ou os artigos que ofereçam riscos à segurança pública. A ANTT ressalta que há cargas consideradas perigosas, mas que não são constituídas de produtos perigosos, como exemplo as cargas com dimensões superiores àquelas determinadas no Código de Trânsito Brasileiro. Contudo, todo produto perigoso é uma carga perigosa.

Os produtos perigosos são categorizados, segundo a Companhia de Tecnologia de Saneamento Ambiental (CETESB), conforme classificação adotada pelas Nações Unidas (classes de 1 a 9) para o transporte deste tipo de produto, revisada em 1991. Outro critério utilizado para essa classificação baseiase no risco ao fogo e no perigo quanto à inflamabilidade, perigo quanto à instabilidade (reatividade) e perigos especiais (como exemplo uma reatividade incomum com a água e propriedades oxidantes). A ANTT aponta que o produto será considerado perigoso se for enquadrado em uma das classes estabelecidas na Portaria no 204, de 20/05/1997, baseada no tipo de risco estabelecido pelas Nações Unidas. 
A regulamentação do transporte segue duas linhas: a econômica e a de segurança (LAMBERT et al., 1998). A econômica afeta as decisões comerciais, enquanto a de segurança está relacionada com a mão-de-obra e condições de trabalho, manutenção de veículos, seguros e prevenção de acidentes. No que se refere aos produtos perigosos, a regulamentação do transporte é complexa, tendo diversas portarias e decretos, assim como a revisão dos mesmos, que tratam do assunto. As Nações Unidas recomendam uma revisão da legislação a cada dois anos, baseando-se na dinâmica das mudanças nas formulações e fabricação dos produtos.

Viana (2000) aponta que o desconhecimento da regulamentação e a falta de informações técnicas são problemas constantes no transporte de produtos perigosos. Tal desinformação pode comprometer as operações logísticas, no que se refere ao cumprimento da legislação vigente e a precaução com possíveis acidentes.

Os cuidados com produtos perigosos envolvem a identificação das unidades de transporte, padrões de embalagem, estacionamento e rota de tráfego dos veículos e tanques de armazenagem. O produto perigoso deverá ser acondicionado de forma a suportar os riscos de carregamento, transporte, descarregamento e transbordo, sendo o expedidor responsável pela adequação do acondicionamento segundo especificações do fabricante.

Dentre as principais causas de acidentes que ocorrem com o transporte rodoviário de produtos perigosos nas estradas paulistas, destacam-se os erros do condutor e as falhas com o veículo, representado $44,3 \%$ e $21,83 \%$ dos acidentes, respectivamente (FERREIRA, 2003). Segundo dados da Polícia Rodoviária Federal levantados por Ferreira (2003), os erros dos condutores mais comuns são a falta de atenção, excesso de velocidade e desobediência à sinalização. Embora haja exigências específicas para a habilitação dos condutores no transporte desses produtos, Ferreira chama a atenção para o fato de encontrar condutores envolvidos em acidentes com certificados de capacitação vencidos ou sem possuírem certificado de habilitação específica. Pelo lado da falta de condições dos veículos, destacam-se a falta de equipamentos de proteção, falta de conjunto de emergência e, até mesmo, veículos sem extintor. A idade média da frota e a falta de atualização tecnológica são outros fatores que indicam condições inadequadas dos veículos que transportam produtos perigosos e que aparecem nas estatísticas de acidentes rodoviários.

\subsection{Logística de combustíveis}

Dentre os produtos perigosos encontram-se os combustíveis, com destaque, pelo volume movimentado, os óleos, gases, gasolina e álcool combustível. Atualmente, existem cerca de 35 mil postos no Brasil (50\% localizados na Região Sudeste, e na Região Sul estão instalados 21\%) e 269 distribuidoras com autorização para funcionar no País, mas apenas 180 delas estão em operação porque o número excessivo faz com que muitas dessas empresas sobrevivam na ilegalidade, principalmente na distribuição de álcool.

Segundo dados da ANP - Agência Nacional do Petróleo, as vendas em 2006 das distribuidoras dos combustíveis derivados de petróleo totalizaram, naquele ano, 90.409.166 metros cúbicos, dos quais 44.258 .752 se referem à Região Sudeste e 25.868.970 ao Estado de São Paulo, e a taxa de variação entre 2005 e 2006 foi de 1,9 \% (ANP, 2007).

$\mathrm{O}$ manuseio, a armazenagem e o transporte dos combustíveis necessitam de cuidados especiais, que significam prevenção de ocorrência de acidente. Ballou (1993) aponta que o bom gerenciamento do manuseio e armazenagem pode resultar, além de segurança no processo operacional, em percepção dos clientes do comprometimento com a qualidade e consequente fidelização com a empresa. Assim, é possível compreender a importância dos cuidados na logística dos combustíveis, a fim de evitar perdas, multas por descumprimento da legislação e fragilização da imagem da empresa.

Gargalos existentes na logística de combustíveis são apontados por Figueiredo (2006) como responsáveis por onerar os elos da cadeia de suprimento da gasolina, álcool e diesel, afetando os preços para o consumidor final. Em um estudo realizado para o Instituto Brasileiro de Petróleo (IBP), os principais gargalos de infraestrutura identificados foram a falta de capacidade das ferrovias para atender à demanda atual e futura e as condições precárias das rodovias. Adicionalmente, Figueiredo (2006) coloca que a escala do sistema atual e o alto custo do capital no Brasil desfavorecem os investimentos em dutos como alternativa para melhorar a infraestrutura da logística de combustíveis. Apesar disso, a autora considera que não se deve descartar essa alternativa como impulsionadora do crescimento da economia, podendo fazer parte do planejamento político de desenvolvimento de algumas regiões.

Keedi e Mendonça (2000) pontuam que as embalagens para transporte de produtos perigosos devem ser analisadas juntamente com o transportador, pois na ocorrência de sinistro, o transportador também será responsabilizado. Tal comunhão de responsabilidades é descrita no Projeto de Lei no 2313, de 2003, o qual altera dispositivos do DecretoLei $\mathrm{n}^{\circ}$ 73, de 21 de novembro de 1966, acrescentando a responsabilidade civil de poluidor à pessoa física ou jurídica caso ocorra um sinistro que cause danos às pessoas e ao meio ambiente.

As agências estaduais e o governo federal assumem papel fundamental para garantir a integridade do meio ambien- 
te e o bem estar da sociedade por meio de fiscalizações e monitoramento contínuo dos postos de distribuição de combustíveis (BRITO et al., 2005). Estes autores observam que, em alguns Estados brasileiros, as legislações estaduais necessitam ser mais restritivas e, em outros, especialmente nas Regiões Norte, Nordeste e Centro-Oeste, onde a discussão do tema ainda não é efetiva, é preciso a criação de legislações específicas.

A preocupação com a proteção do meio ambiente tem se revelado gradual e paulatinamente e torna-se mais rígida, com legislações mais rigorosas que incluem severas multas aos infratores. As exigências em relação aos postos de gasolina aumentaram, quando estes foram incluídos na lista dos potenciais poluidores com base na Lei de Crime Ambiental no 9605, promulgada em 12 de fevereiro de 1998. Os postos de gasolina ficaram ainda mais em evidência com a edição da Resolução do Conselho Nacional de Meio Ambiente no 273, de novembro de 2000 (CONAMA, 2000), que dispõe sobre armazenamento e vazamentos de derivados de petróleo.

O condutor do veículo deverá possuir as qualificações e habilitações previstas na legislação de trânsito, assim como receber treinamento específico para o transporte desse produto, de acordo com as instruções do Conselho Nacional de Trânsito (CONTRAN). O credenciamento é efetuado após a realização do curso de Movimentação de Produtos Perigosos (MOPP), no qual o profissional recebe instruções sobre a lei vigente a respeito do transporte de produtos perigosos, suas inovações, as infrações e penalidades no descumprimento das regras, os horários e itinerários permitidos para circulação.

A armazenagem dos líquidos inflamáveis ocorre em tanques específicos, os quais possuem equipamentos que, em caso de acidentes, são acionados, reduzindo as probabilidades de alastramento do desastre. A periculosidade dos líquidos inflamáveis leva os órgãos responsáveis a criar normas que regulamentam as armazenagens desses produtos, como a norma regulamentadora NR 20 e a NBR 7505 da ABNT (Associação Brasileira de Normas Técnicas). A regulamentação visa à segurança do local e dos funcionários envolvidos nos processos, do meio ambiente e dos terceiros que possam ser envolvidos em acidentes involuntariamente.

As empresas devem se preocupar com a segurança de seus tanques, uma vez que, depois de instalados, torna-se difícil a verificação de vazamentos, sendo estes detectados apenas pelo controle de estoque e pelas revisões e manutenções que devem ocorrer periodicamente. Apesar de ser obrigatória a existência de diques de contenção, é importante essa revisão, pois, em casos mais alarmantes, o dique poderá não ser suficiente para conter o vazamento e o produto poderá contaminar o lençol freático, prejudicando drasticamente o meio ambiente.

A contaminação de águas subterrâneas por derramamento de gasolina agrava-se à medida que aumenta o risco de se atingir uma fonte receptora, como por exemplo um poço de abastecimento de água. Corseuil e Marins (1997) apontam para a identificação do nível de risco como parâmetro para decisão de se utilizar tecnologias de remediação ativa, como a extração de vapores do solo ou a biorremediação com

\section{s cuidados com produtos perigosos envolvem a de embalagem, estacionamento e rota de tráfego dos veículos e tanques de armazenagem.}

injeção de oxigênio e nutrientes, que devem ser empregadas apenas nos casos em que o risco é mais elevado. Portanto, um mapeamento de risco de contaminação torna-se prioridade, o qual estará sob a responsabilidade tanto das empresas potencialmente poluidoras quanto dos órgãos de controle ambiental. Os mesmos autores também colocam a utilização da remediação natural como ação a ser incorporada às estratégias de recuperação de áreas degradadas a fim de redução de altos investimentos para evitar a migração dos contaminantes até locais receptores.

Além dos aspectos levantados por Corseuil e Marins (1997), Favero et al. (2007) acrescentam que a contaminação das águas subterrâneas também estará sujeita à extensão do derramamento de algum poluente e das propriedades físicas do solo e do próprio poluente. Segundo Favero et al. (2007), aquíferos subterrâneos que abastecem indústrias e cidades têm sido contaminados frequentemente por acidentes que ocorrem com petróleo e seus derivados.

\subsection{Descarte de materiais}

Nos últimos anos a atenção ao descarte de sucata, excedentes e materiais recicláveis ou resíduos em geral, tem aumentado consideravelmente e deixado de ser um assunto casual (LAMBERT et al., 1998). Isto se deu, principalmente, pela crescente preocupação das empresas em atender às pressões de um público cada vez mais consciente com a questão do meio ambiente e de legislações governamentais mais rigo- 
rosas. O descarte de materiais é algo frequentemente observado nas empresas, como resultado das condições técnicas de suas operações. O objetivo é dar aos resíduos um destino ambientalmente correto tão logo sejam gerados.

São significativos os avanços na busca da redução, reuso ou reciclagem dos diversos materiais utilizados nos processos de produção que geram os seus produtos. Muitas indústrias têm buscado a reutilização de materiais, diminuindo o impacto ao ambiente causado pelo descarte após o uso dos produtos e reduzindo o número de aterros para este fim (GUIDE et al., 2000). Este sistema, já amplamente utilizado em países desenvolvidos como na Europa e nos Estados Unidos, além de contribuir para o desenvolvimento sustentável, tem se tornado uma oportunidade de aumento da lucratividade. Todavia, os autores reconhecem que o processo de planejamento e controle da produção utilizando materiais recuperados é complexo, tendo em vista dificuldades como incerteza das quantidades e tempo de reposição, equilíbrio entre a disponibilidade e a demanda, acurácia das previsões e desenvolvimento de uma logística reversa.

conhecido como rerrefino, representa uma interessante alternativa e vem sendo adotado por vários países, incluindo o Brasil, com resultados positivos. No entanto, a experiência tem mostrado que os mecanismos de mercado não são suficientes para garantir a existência, em termos sustentáveis, do processo de rerrefino de óleos lubrificantes.

\subsection{Desenvolvimento sustentável}

Uma visão tradicional e reativa no gerenciamento de riscos está dando lugar a uma visão dinâmica e proativa, pela qual o alcance dos objetivos organizacionais, sem surpresas ou tensão, implica em considerar os riscos a todos os stakeholders da organização (LOUISOT, 2003). Trata-se de eliminar uma análise fragmentada, quer por departamentos ou por atividades, em direção à integração da organização com seus stakeholders, internos e externos.

A visão baseada na eficiência indicava que a única responsabilidade social da empresa seriam os lucros, limitando-se a obedecer a lei (RODRIGUEZ et al., 2002). Ainda é possível observar que esta visão permanece em alguns setores empresariais conservadores (DONAIRE, 1999), em que os administradores concentram-se apenas no funcionamento da empresa sob aspectos econômicos, ficando de lado aspectos mais amplos do contexto sociopolítico. Mascarenhas (2004) aponta que a visão limitada dos gestores em procurarem adequar-se às legislações está presente no setor de distribuição e comercialização de com-

É cada vez mais frequente um maior número de indústrias de manufatura dando atenção específica ao descarte de materiais, principalmente em países de grande consumo e, em consequência, grandes geradores de lixo. Muller (1991) aponta que empresários da indústria já não consideram os gastos com a preservação do meio ambiente como custos adicionais, mas como inerentes das operações em um mundo no qual os recursos tendem a não ser suficientes para atender às necessidades da população. Em se tratando dos resíduos de combustíveis, os efluentes necessitam de tratamentos que podem utilizar separadores de água e óleo, lagoas de tratamento e aeração constante do sistema que estimula a degradação dos poluentes orgânicos. A limpeza dos veículos utilizados no transporte realiza-se em locais em que os resíduos possam ser isolados.

Tristão et al. (2005) estudaram o gerenciamento ambiental de resíduos de óleos lubrificantes usados e o risco de degradação ambiental quando descartados indevidamente ou utilizados como combustível em estabelecimentos industriais. O processo de reciclagem de óleos lubrificantes, bustíveis, ficando o gerenciamento ambiental periférico ao planejamento estratégico dessas empresas.

Por outro lado, a visão apresentada por Rodriguez et al. (2002) traz a ideia do desempenho social da corporação, na qual se inserem os caminhos utilizados pela organização para suas ações diante das demandas sociais e que justificam assumir ou não seu papel socialmente responsável em busca dos resultados desejados. De acordo com Rossi et al. (2000), a sustentabilidade dos negócios não é apenas resultado de suas atividades comerciais, mas também um processo social que requer a contínua construção e gerenciamento de novas capacidades. É um processo que envolve os líderes e empregados das organizações, a comunidade e o setor público. Considerando que as organizações não podem operar independentemente dos sistemas sociais e naturais, é condição inerente para a sobrevivência a integração entre estes sistemas.

O desenvolvimento de novos recursos, capacidades e atividades (RODRIGUEZ et al., 2002; ROSSI et al., 2000; CAJAZEIRA; BARBIERI, 2006), embora específico para 
cada tipo de negócio, estabelecerá o desenvolvimento dos recursos sociais, o que resultará do estabelecimento de novas relações da organização com seus stakeholders. O desafio que as organizações passam a ter é desenvolver novas formas de operar em cooperação com seus fornecedores, clientes e outros stakeholders, incluindo os concorrentes (ELKINGTON, 1994).

Hartman et al. (1999) enfatizam a necessidade do estabelecimento de parcerias para o alcance da sustentabilidade, $o$ que implica em uma série de trocas (intercâmbios) entre os diversos setores da sociedade. As parcerias podem resultar em inovações industriais que contemplem os ciclos de vida de produtos e o gerenciamento ambiental, além do estabelecimento de novos valores sociais. Os autores destacam que alianças entre indústria, governo, ONGs e a sociedade são necessárias para gerar políticas e mercados compatíveis com a sustentabilidade, dentro de um novo modelo que inclui produção e consumo sustentáveis.

Welsh e Herremans (1998) destacam que, ao planejar uma estratégia que contemple o desenvolvimento sustentável, é necessário considerar os interesses dos diversos stakeholders. Esses interesses incluem o desenvolvimento da economia local, educação e participação da comunidade na movimentação da economia gerada pelo funcionamento do negócio e a criação de sistemas de controle ambiental que autorregulem as operações da empresa. Problemas ambientais graves, como perda de biodiversidade, desertificação, aquecimento global, poluição dos oceanos e precipitações ácidas, levam a uma descrença generalizada quanto às reais intenções das empresas de um modo geral, tornando-as alvos de críticas e colocando-as em descrédito diante da opinião pública (CAJAZEIRA; BARBIERI, 2006).

A integração da organização com seus diversos stakeholders combina com o atendimento às pressões econômicas, ambientais e sociais, que têm se tornado cada vez mais frequentes (SANDELANDS, 1994). Este autor questiona o aumento da eficiência conseguida nas indústrias, especialmente nas automotivas, que adotaram técnicas como a da produção enxuta, à custa das pessoas, do meioambiente e da própria indústria.

Sandelands (1994) baseia-se em estudos realizados no Japão em 1991 pela JAW (the National Federation of Unions in the Automotive Japanese Industry), em que se observou que mais de $60 \%$ dos empregados da indústria automotiva consideravam as demandas de trabalho excessivas, viam o trabalho como muito rotineiro e acreditavam que as empresas davam pouca atenção ao desenvolvimento dos recursos humanos. O autor utiliza estes estudos para levantar a hipótese de que doenças ocupacionais ou o estresse dos trabalhadores estariam relacionados à utilização de técnicas como a produção enxuta, embora ele admita que não haja evidências que comprovem tal relação.

A conjunção do desenvolvimento sustentável e do crescimento econômico é vista por Rossi et al. (2000) como resultado de uma mudança radical das organizações. Os autores colocam as empresas, em especial as multinacionais, que se enquadram numa visão corporativa, e o setor público, que representa a visão pública, como principais agentes para que ocorra o desenvolvimento sustentável. Pela visão corporativa, a expansão econômica dos negócios levaria melhores condições de vida a toda população, que consumiria produtos resultantes de inovações científicas voltadas ao desenvolvimento sustentável. Contudo, questiona-se a capacidade das empresas em adotar estas mudanças. Neste momento, entra a visão pública, a qual garantiria as mudanças por meio de leis e pressões da sociedade civil.

\section{A o planejar uma estratégia que contemple o Idesenvolvimento sustentável, é necessário considerar os interesses dos diversos stakeholders}

Cabe indagar se em países em desenvolvimento, onde uma pequena massa tem acesso privilegiado no governo, as leis não buscariam apenas dar sustentação para que as empresas atinjam seus objetivos econômicos (DONAIRE, 1999). Todavia, Donaire (1999) acrescenta que as influências do ambiente externo têm aumentado, especialmente de caráter social, ambiental, segurança e defesa de grupos minoritários. Neste contexto, Muller (1991) ressalta que se as empresas tomarem a frente na busca por soluções, como no gerenciamento dos descartes industriais, menor será a intervenção do Estado, o que, por vezes, implica em apanhar as empresas despreparadas para cumprir as exigências governamentais.

Assim, a sustentabilidade implica em uma radical quebra do modelo atual de produção e consumo (HARTMAN et al., 1999). Contudo, Veleva et al. (2003) constataram, em sua pesquisa, que ainda são poucas as empresas de produção que têm suas operações orientadas para o desenvolvimento sustentável.

Não parece que ações individuais e solitárias sejam suficientes para as mudanças mencionadas. Hartman et al. (1999) veem a necessidade de uma ampla colaboração. A colaboração implica em interdependência entre os stakehol- 
ders, manutenção construtiva das diferenças, decisões coletivas e responsabilidade compartilhada dos resultados. Requer stakeholders engajados em um entendimento comum a respeito dos problemas ambientais para que haja troca de pontos de vista. Bloemhof et al. (1995), assim como Donaire (1999), destacam a importância dos tomadores de decisão das empresas conhecerem modelos para lidar com questões ambientais, uma vez que, segundo os autores, por vezes o crescimento econômico é posto em conflito com o desenvolvimento sustentável e a qualidade ambiental.

Ao respeitar as práticas ambientais, independente da atividade, a organização tem a oportunidade de mostrar sua preocupação com a saúde da população e dos seus funcionários, realizando investimentos que visem à preservação do ecossistema e à melhoria da qualidade de vida. Deixa-se de considerar a proteção ao meio ambiente apenas como exigência que, quando não cumprida, é punida com multas e sanções, passando a ser algo estratégico nos negócios, ou seja, pode representar posições em relação à concorrência em resposta a oportunidades ou ameaças no mercado (ANDRADE et al., 2000).

\section{PROCEDIMENTOS METODOLÓGICOS}

O presente estudo tem um caráter nitidamente exploratório que, segundo Cervo e Bervian (2001), objetiva a familiarização do pesquisador com o fenômeno, a ampliação do conhecimento ou a obtenção de nova percepção do mesmo. É um tipo de pesquisa flexível e versátil e não estruturado que não visa à confirmação de hipóteses, mas à descoberta de novas ideias.

O método de pesquisa utilizado foi o qualitativo, indicado quando se está lidando com problemas pouco conhecidos e a pesquisa é de cunho exploratório (GODOY, 1995). Um método comumente utilizado em pesquisa não conclusiva e quando não é possível, ou conveniente, a obtenção de dados por meio de métodos estruturados. A pesquisa qualitativa possibilita, ainda, conhecer valores, emoções e motivações que estão no subconsciente dos respondentes.

Para a coleta de dados foram realizadas entrevistas. A entrevista não é uma simples conversa, mas sim um método de investigação orientado para um objetivo definido, a fim de obter do informante dados relevantes para a pesquisa (CERVO; BERVIAN, 2001). Seguiu-se um roteiro semiestruturado, o que permite ao pesquisador aprofundar a investigação durante a realização das entrevistas. Todo o roteiro foi construído com base na revisão da literatura e focado em responder aos objetivos desta pesquisa. Por ser uma pesquisa exploratória, após as primeiras entrevistas novos elementos revelados pelos respondentes e considerados importantes para a ampliação da compreensão do fenômeno, foram acrescentados ao roteiro e aplicados aos demais entrevistados. É uma maneira de manter o entrevistado focado no conteúdo específico e de obter respostas significativas para desvendar problemas ocultos.

As entrevistas foram realizadas com funcionários de uma grande distribuidora de combustíveis da região metropolitana de São Paulo, caracterizando um estudo em profundidade e não em extensão. As pessoas selecionadas para responder às entrevistas foram gerentes ou encarregados ligados aos processos logísticos da empresa, do departamento de recursos humanos e segurança do trabalho, num total de oito entrevistados.

As entrevistas foram gravadas e posteriormente transcritas literalmente. A partir das transcrições das entrevistas, realizou-se uma análise de conteúdo através da categorização das falas dos respondentes. Segundo Malhotra (2001), a análise de conteúdo é bastante útil quando os dados são obtidos por meio da comunicação e não são resultado de observação comportamental ou objetos físicos. $\mathrm{Na}$ análise de conteúdo são elaboradas categorias analíticas utilizadas para a classificação dos dados e a comunicação é decomposta conforme regras preestabelecidas.

\subsection{Resultados e Análise dos Dados}

A partir das entrevistas realizadas, partiu-se para a análise de conteúdo, fazendo-se a categorização dos dados em duas etapas: (1) a priori e (2) a posteriori. A priori foram definidas três grandes categorias com a intenção de identificar os conceitos e as ações que a empresa utiliza em seu negócio e que se inserem dentro do contexto de desenvolvimento sustentável. A definição das categorias a priori objetivou também a elaboração do roteiro utilizado nas entrevistas, orientando a coleta de dados. Definiram-se então as categorias: a) operações logísticas (recebimento e distribuição, armazenagem e descarte de resíduos); b) meio ambiente; e c) pessoas.

A partir das informações obtidas, observou-se que, subjacente a cada categoria, os entrevistados deram grande ênfase aos riscos de ocorrerem acidentes, às ações preventivas e às ações corretivas. Assim, novas categorias puderam ser estabelecidas e inseridas em uma matriz para que seus elementos-chaves fossem cruzados com as categorias definidas a priori e já apresentadas.

A análise de conteúdo obedeceu às seguintes etapas: organização do material, leitura preliminar, codificação, determinação das unidades de registro, determinação das unidades de contexto, categorização e redação do texto (BARDIN, 1977). As unidades de registro foram as frases dos entrevistados, enquanto as unidades de contexto foram as categorias 
previamente definidas. Na categorização, utilizaram-se como critério as ênfases dadas pelos entrevistados em suas respostas, a repetição de frases e/ou ideias similares e prontidão ou demora em responder às questões. A categorização das entrevistas está esquematizada no Quadro 1:

Pelo Quadro 1 é possível observar que os riscos mais frequentes na distribuidora são a possibilidade de explosão e de vazamento. Observou-se, também, que o risco de vazamento foi citado nas operações logísticas (no recebimento e distribuição e na armazenagem) e também nos riscos ao meio ambiente, isto é, sua amplitude é maior que o risco de explosão, citado apenas nas operações logísticas.

É interessante notar que, em se tratando dos riscos às pessoas, o risco à vida pode trazer implícita a ideia de diversas causas, as quais foram apontadas como riscos nas demais categorias, como incêndio, explosão e acidentes rodoviários. Ou seja, os riscos apontados em outras categorias deixam de ser fim e passam a ser causadores de danos à vida das pessoas.

Em relação à prevenção de acidentes, observa-se pelo Quadro 1 as maiores frequências em que se mencionou o cumprimento às normas, o treinamento e o uso de equipamentos de proteção individual (EPIs). Tendo em vista que o uso de EPIs também é um cumprimento às normas de segurança, as pessoas entrevistadas deram grande ênfase ao conhecimento e obediência às normas vigentes para as operações com combustíveis. Uma preocupação que é estendida aos colaboradores envolvidos em tais operações por meio de treinamentos, onde além de transmitir informações a respeito das normas e legislações, busca-se a conscientização de todos, ressaltando as consequências da ocorrência de acidentes.

$\mathrm{Na}$ distribuidora pesquisada, as ações corretivas, em caso de acidentes, têm características bastante semelhantes à prevenção de acidentes. As maiores frequências observadas ao longo das entrevistas foram o cumprimento às normas, o uso de EPIs e o treinamento. Observou-se que, embora o objetivo seja a prevenção, os operadores devem estar preparados para agir no caso de ocorrência de acidentes, também com base nas normas e legislação vigente.

\subsection{Interpretação dos Resultados}

A seguir, tomando por base a análise de conteúdo das entrevistas, é apresentada a interpretação dos resultados, explorando cada uma das categorias.

\subsection{Recebimento e Distribuição}

Tanto nas operações de recebimento como de distribuição, os entrevistados enfatizaram o risco de explosão, inerente ao processo pelas próprias características dos combustíveis.

Quadro 1: Matriz de categorias e palavras-chaves.

\begin{tabular}{|c|c|c|c|}
\hline & Riscos & Ações Preventivas & Ações Corretivas \\
\hline $\begin{array}{l}\text { Operações } \\
\text { Logísticas } \\
\text { (Recebimento e } \\
\text { distribuição) }\end{array}$ & $\begin{array}{l}\text { Explosão, } \\
\text { vazamentos, } \\
\text { acidentes } \\
\text { rodoviários }\end{array}$ & $\begin{array}{l}\text { Uso de EPIs, instalações elétricas, uso de aparelhos } \\
\text { eletrônicos, sinalização do veículo, identificação } \\
\text { do produto, manutenção dos caminhões, normas, } \\
\text { Resoluções da ANP, treinamento }\end{array}$ & $\begin{array}{l}\text { Uso de EPIs, plano de controle de } \\
\text { emergência, sinalização do } \\
\text { veículo, identificação do produto, } \\
\text { normas, Resoluções da ANP, } \\
\text { treinamento. }\end{array}$ \\
\hline $\begin{array}{c}\text { Operações } \\
\text { Logísticas } \\
\text { (Armazenagem) }\end{array}$ & $\begin{array}{c}\text { Explosão, } \\
\text { vazamentos }\end{array}$ & $\begin{array}{c}\text { Uso de EPIs, instalações elétricas, } \\
\text { normas da ONU, métodos da ABNT, } \\
\text { uso de aparelhos eletrônicos, medição } \\
\text { dos tanques, inspeção de equipamentos, } \\
\text { treinamento }\end{array}$ & $\begin{array}{l}\text { Uso de EPIs, normas da ONU, } \\
\text { treinamento }\end{array}$ \\
\hline $\begin{array}{l}\text { Operações } \\
\text { Logísticas } \\
\text { (Descarte de } \\
\text { Resíduos) }\end{array}$ & $\begin{array}{l}\text { Incêndio, } \\
\text { explosão, vida e } \\
\text { meio ambiente }\end{array}$ & $\begin{array}{c}\text { Contratação de empresa habilitada, } \\
\text { utilização de tambores, processo de } \\
\text { tratamento de vapores, normas, política } \\
\text { ambiental }\end{array}$ & Uso de EPIs, normas, treinamento \\
\hline Meio Ambiente & $\begin{array}{l}\text { Vazamentos, } \\
\text { danos ao meio } \\
\text { ambiente }\end{array}$ & $\begin{array}{c}\text { Processo de tratamento de vapores, } \\
\text { legislação, normas, esclarecimento das } \\
\text { consequências de acidentes aos } \\
\text { colaboradores, ações e atitudes dos } \\
\text { colaboradores }\end{array}$ & $\begin{array}{l}\text { Normas, plano de controle } \\
\text { de emergência }\end{array}$ \\
\hline Pessoas & $\begin{array}{l}\text { Acidentes, risco } \\
\text { à vida }\end{array}$ & $\begin{array}{l}\text { Normas, uso de EPIs, treinamento, } \\
\text { reciclagem de treinamento, inspeção de } \\
\text { veículos e equipamentos }\end{array}$ & $\begin{array}{l}\text { Normas, uso de EPIs, } \\
\text { treinamento, reciclagem de } \\
\text { treinamento }\end{array}$ \\
\hline
\end{tabular}

Fonte: Elaborado pelos autores 
A distribuidora estudada recebe o álcool combustível das usinas localizadas em São Paulo credenciadas por meio de caminhões-tanque, enquanto a gasolina e o óleo diesel são recebidos via oleodutos, com bombeamentos programados e previamente informados.

O principal agente de risco apontado no processo de recebimento dos combustíveis foi a maneira como os operadores realizam a operação. Antes da armazenagem do produto, é coletada uma amostra do produto para que técnicos especializados verifiquem a qualidade, para posterior aprovação ou rejeição. Relatou-se ainda, a importância da comunicação, pela qual é possível prevenir que um bombeamento não esperado ou mal administrado ocasione vazamento do produto. Ainda em relação às operações de recebimento, a tecnologia dos equipamentos utilizados, tanto no transporte rodoviário como dutoviário, foi apontada como elemento redutor dos riscos de acidentes. Vale lembrar que a falta de adequação tecnológica dos veículos de transporte de produtos perigosos foi apontada por Ferreira (2003) como causa frequente de acidentes rodoviários.

namento de seus colaboradores. O grande enfoque é dado ao cumprimento da legislação vigente, no que diz respeito à identificação dos equipamentos, veículos e produto transportado, manutenção dos veículos, restrição ao uso de equipamentos elétricos, utilização de EPIs, estacionamento dos veículos em locais apropriados e horários de trânsito permitido. Neste aspecto, é possível fazer uma associação com o papel da organização e do poder público como agentes das ações em direção ao desenvolvimento sustentável (ROSSI et al., 2000; BRITO et al., 2005).

A fim de que as instruções sejam seguidas, a empresa dá importância destacada à educação de seus colaboradores. À medida que as pessoas se tornam mais conscientes de seu papel na prevenção e as consequências causadas pelos acidentes, é reforçada a relevância de ações socialmente responsáveis, o que revela uma situação diferente da apresentada por Mascarenhas (2004).

A importância dada ao treinamento e educação dos colaboradores para a prevenção é estendida às ações corretivas em caso de acidentes. Também os aspectos normativos e legais foram destacados nas ações corretivas como a utilização de uma ficha informativa das características do produto, utilização de EPIs, comunicação do acidente aos órgãos competentes e à própria empresa. Em caso de acidentes, a empresa possui um plano de controle de emergência e pessoas devidamente

A distribuição dos combustíveis é feita por empresas terceirizadas ou pela própria frota de caminhões da distribuidora, contudo, o agente transportador não foi apontado pelos entrevistados como tendo relação direta ao risco de acidente. Isto não descarta, porém, o estudo em conjunto citado por Keedi e Mendonça (2000), onde contratante e contratada devem analisar as condições do transporte de produtos perigosos, uma vez que ambas as partes são responsabilizadas em caso de sinistro. Segundo os entrevistados, os maiores riscos de acidentes no transporte dos combustíveis dão-se pelas más condições das estradas brasileiras associadas a possíveis atos negligentes dos condutores dos veículos. Esta última constatação diverge em parte dos dados informados pela Polícia Rodoviária Federal, que apontam os erros do condutor do veículo, mas deixa de lado as condições das rodovias entre as principais causas de acidentes rodoviários com produtos perigosos (FERREIRA, 2003). Por outro lado, Figueiredo (2006) chama a atenção para as condições precárias das rodovias brasileiras como um dos gargalos na logística de combustíveis.

Como medidas preventivas, a empresa ocupa-se na elaboração de rigorosos procedimentos operacionais e trei- treinadas são enviadas ao local para as ações necessárias, como isolamento da área, contenção de vazamentos e reparos dos equipamentos.

\subsection{Armazenagem}

Os riscos destacados pelos entrevistados na armazenagem dos combustíveis são de vazamento e explosão. $\mathrm{O}$ armazenamento ocorre em tanques especiais, os quais podem ser de teto fixo ou flutuante, sendo que o segundo oferece a vantagem de demonstrar o nível de armazenamento do produto à medida que sua tampa abaixa em relação à distribuição do combustível. Estes tanques passam por testes de estanqueidade, o qual detecta se os mesmos estão com vazamento.

A fim de minimizar os riscos na armazenagem e evitar a ocorrência de acidentes, os entrevistados ressaltaram a importância de acompanhar as constantes mudanças na legislação e suas influências sobre os processos operacionais (VIANA, 2000). A empresa possui sistema de detecção de vazamento automático, o qual possibilita a redução dos riscos de acidentes, fornece e fiscaliza a utilização de EPIs, utiliza equipamentos elétricos a prova de 
explosão, desenvolve um plano de tratamento de vapores e dá grande ênfase ao treinamento das pessoas envolvidas nas operações.

Os entrevistados relataram que a ocorrência de acidentes dentro da empresa é pequeno, resultado das medidas preventivas adotadas. Contudo, quando ocorre um acidente, a organização possui um Plano de Controle de Emergência, para diminuir os danos que o produto pode proporcionar ao ambiente, aos funcionários e à comunidade.

Cabe aqui destacar a importância que os entrevistados deram ao cumprimento dos procedimentos escritos no manuseio dos produtos armazenados, uma orientação que não se limita à preocupação com a segurança, mas também com a qualidade destes produtos. São cuidados com as atividades logísticas que podem evitar acidentes que seriam prejudiciais à imagem da empresa, tanto pela perda de qualidade do produto quanto pela descrença das reais intenções da empresa percebida pela opinião pública (CAJAZEIRA; BARBIERI, 2006).

\subsection{Descarte de resíduos}

Os entrevistados revelaram que a preocupação da empresa com o descarte de resíduos tem aumentado, acompanhando uma tendência da sociedade, especialmente dos ambientalistas (LAMBERT et al., 1998; SANDELANDS, 1994; DONAIRE, 1999). Estes resíduos não podem ser "jogados" no meio ambiente sem cuidados particulares. Assim como nos processos de armazenagem, recebimento e distribuição, há o risco de explosão, e ainda os danos causados ao meio ambiente e à vida. $\mathrm{O}$ processo de descarte de resíduos iniciase com a separação ao serem retirados dos tanques, depois ocorre a embalagem em tambores, o transporte, a destruição em fornalhas e, finalmente, a documentação da efetiva destruição dos mesmos.

A distribuidora contrata uma empresa especializada e homologada neste tipo de operação e é auditada pelo órgão competente, a Companhia de Tecnologia de Saneamento Ambiental (CETESB). Faz-se necessária a confirmação de destruição dos resíduos, para evitar o descarte desses materiais no meio ambiente. Uma violação deste procedimento pode acarretar sérios riscos à vida humana e ao meio ambiente, além de elevadas multas e prejuízo à imagem da própria distribuidora (LAMBERT et al., 1998; CAJAZEIRA; BARBIERI, 2006).

\subsection{Meio Ambiente}

A atenção dada à questão ambiental permeia todas as operações da distribuidora estudada. Foram destacados os riscos de vazamentos e danos ao meio ambiente. $\mathrm{Na}$ realidade, notou-se que a preocupação com os danos am- bientais reflete os cuidados com a prevenção nos processos operacionais já destacados.

Atualmente, a empresa utiliza um processo de tratamento de vapores, que são gases provenientes dos processos de recebimento, armazenagem e distribuição. Este processo consiste em recuperar os vapores provenientes do carregamento e descarregamento de combustíveis nos tanques e nos caminhões utilizados pela empresa. Como destacado por Guide et al. (2000) e Muller (1991), há uma tendência de crescimento do número de empresas orientadas a recuperar seus descartes como preocupação ambiental e como oportunidade estratégica de aumento da lucratividade (ANDRADE et al., 2000). Os vapores ou gases eliminados pela operação da empresa também podem ser eliminados por meio de combustão em unidades de oxidação térmica.

A velocidade na ação corretiva é fundamental para a redução dos impactos ao meio ambiente, caso ocorra um acidente. Citou-se, como exemplo, a possibilidade de um vazamento que possa ocorrer próximo a um rio ou lago, que, se constatado a princípio, pode ser remediado para que não gere consequências piores. Esta é uma situação que indica a importância do mapeamento de risco citado por Corseuil e Marins (1997) para que sejam priorizadas as áreas próximas a uma fonte receptora para a priorização de ações de prevenção de acidentes com gasolina.

Embora não tenham sido revelados números, foram destacados os investimentos da empresa em equipamentos, desenvolvimento de novos processos e conscientização através de treinamento e educação dos colaboradores, para a preservação do meio ambiente. São ações que são orientadas a uma mudança no modelo tradicional da cadeia de produção e consumo, como citado por Hartman et al. (1999). Os entrevistados mostraram estar conscientes de que os recursos oferecidos pelo meio ambiente são escassos e, portanto, merecem cuidados para que haja um desenvolvimento sustentável (RODRIGUEZ et al., 2002; CAJAZEIRA; BARBIERI, 2006).

\subsection{Pessoas}

As entrevistas revelaram que, assim como ocorreu na categoria meio ambiente, os riscos que envolvem as pessoas são decorrentes dos processos operacionais da distribuidora. Vale destacar que os entrevistados consideram as pessoas como importantes agentes nos riscos mencionados. Ou seja, as pessoas são fundamentais para que um acidente ocorra ou não. Isto conduz, então, a uma atenção especial da empresa no que se refere à conduta de seus colaboradores.

Os entrevistados enfatizaram o grande número de treinamentos que a empresa oferece aos colaboradores para a 
prevenção de acidentes. Neste sentido, merecem destaque o treinamento para movimentação de produtos perigosos (MOPP), palestras periódicas de conscientização, conhecimento das normas em vigência e utilização de EPIs, sendo o MOPP e o uso de EPIs aqueles mencionados com maior frequência pelos entrevistados. Ações simples, como não fumar e não utilizar aparelhos eletrônicos nas áreas de risco, significam menores possibilidades de ocorrerem acidentes. As pessoas entrevistadas fizeram questão de destacar que tais treinamentos são oferecidos não apenas para cumprimento de uma exigência legal, mas que a empresa se mostra especialmente preocupada com a segurança e a integridade física de seus colaboradores. Diferente do que foi colocado por Mascarenhas (2004), é possível relacionar este fato a uma nova mentalidade que a empresa está assumindo e que responde às pressões externas da sociedade (DONAIRE, 1999) e a uma antecipação às intervenções do Estado citadas por Muller (1991).

Alguns entrevistados apontaram ainda, que a preocupação da empresa com as pessoas não se restringe a seus colaboradores diretos, mas estende-se aos prestadores de serviços contratados e à comunidade como um todo (ROSSI et al., 2000).

Os treinamentos também foram apontados como fundamentais para que os colaboradores saibam como agir diante da ocorrência de um acidente envolvendo os combustíveis. Há uma orientação para que os colaboradores tenham consciência das consequências de um acidente para eles mesmos, para a sociedade e para o meio ambiente. A partir da conscientização, os envolvidos nas operações com os combustíveis compreendem melhor seu papel e sua responsabilidade quando há um acidente.

Os entrevistados não demonstraram estarem se sentindo forçados ou obrigados a participar dos treinamentos, mas consideram uma "oportunidade de aprender a agir em situações emergenciais".

\section{CONSIDERAÇÕES FINAIS}

A proposta do presente estudo foi permitir uma discussão da importância de compreender como áreas operacionais, como a logística de combustíveis, podem ser abordadas de uma maneira mais ampla, em um contexto social e ambiental, dentro da perspectiva do desenvolvimento sustentável.

Embora o objeto de estudo tenha sido apenas uma distribuidora de combustíveis, os resultados trazem luz para uma reflexão mais cuidadosa no que se refere aos diversos papéis dos stakeholders da organização. São diversas as ati- vidades operacionais que têm relevância para o contexto do desenvolvimento sustentável, tanto no recebimento, como na armazenagem ou distribuição. São atividades que estão regulamentadas por normas legais e orientadas por procedimentos internos da organização, onde a conscientização do pessoal operacional tem papel fundamental para que sejam realizadas de maneira responsável.

Executar atividades operacionais com segurança minimiza o risco de explosões, vazamentos, incêndios e acidentes rodoviários, o que, por consequência, preserva a vida e a integridade física das pessoas, tanto dos funcionários quanto da comunidade e não ataca o meio ambiente. O exemplo da distribuidora de combustíveis estudada pode ser explorado por outras empresas, a fim de visualizarem seus processos logísticos sob a ótica da sustentabilidade.

Como visto na literatura, para que as ações em direção ao desenvolvimento sustentável sejam efetivas é necessário que haja integração entre os diversos stakeholders, evitando-se ações isoladas que tenham pouca abrangência. Neste aspecto, foram bastante ricos os resultados desta pesquisa, que mostraram ações do poder público, o qual regulamenta os serviços logísticos de combustíveis e monitora a evolução dos processos realizados com este tipo de produto. A organização oferece sua contribuição ao desenvolver novas técnicas de manuseio e controle dos processos operacionais, assim como fornecer EPIs, treinamento e desenvolvimento de seus colaboradores para que estes operem com segurança e consciência da importância da prevenção de acidentes que podem ser danosos às pessoas e ao meio ambiente. A sociedade realiza seu papel fazendo pressão para que a organização não descarte os resíduos provenientes de suas operações sem cuidado e que não danifique o meio em que vive. Os fornecedores e clientes agem segundo as normas, assumindo sua responsabilidade em casos de acidentes. E, por fim, os funcionários da distribuidora, que são, em última análise, os responsáveis para que os procedimentos se normatizados e programados sejam cumpridos com segurança, resultado da educação e treinamento que recebem.

Ainda que não seja possível concluir que a estratégia da distribuidora de combustíveis inclua uma orientação para o desenvolvimento sustentável, pode-se dizer que suas ações são favoráveis para a sustentabilidade. Há uma clara preocupação com seus processos operacionais, assim como suas relações com os stakeholders, que se inserem em um processo socioeconômico do qual, como destacaram Rossi et al. (2000), depende a sustentabilidade dos negócios.

Mais uma vez vale lembrar que este estudo teve um caráter exploratório e como tal não permite generalizações, 
o que, todavia não invalida suas contribuições a respeito de um tema que ainda merece investigações mais detalhadas. Uma sugestão para estudos futuros é a verificação de hipóteses que incluam variáveis que relacionem, além dos processos logísticos, os processos produtivos com o desenvolvimento sustentável.

\section{Artigo recebido em 20/06/2007 Aprovado para publicação em 10/10/2008}

\section{REFERÊNCIAS}

AGÊNCIA NACIONAL DO PETRÓLEO. Dados Estatísticos: vendas de combustíveis. Disponível em: <http://www.anp.gov.br>. Acesso em 28 mar 2007.

AGÊNCIA NACIONAL DE TRANSPORTES TERRESTRES. Transporte de Produtos Perigosos. Disponível em:<http://www.antt.gov.br/carga/ pperigoso/pperigoso.asp $>$. Acesso em 14 ago 2008.

ANDRADE, R. O. B.; TACHIZAWA, T. CARVALHO, A. B. Gestão ambiental: enfoque estratégico aplicado ao desenvolvimento sustentável. São Paulo: Makron Books, 2000.

ARGANDOÑA, A. The Stakeholder Theory and the Common Good. Journal of Business Ethics, Dordrecht, v. 17, p. 1093-1102, 1998.

BALLOU, R. H. Logística Empresarial: Transportes, Administração de Materiais e Distribuição Física. São Paulo: Atlas, 1993

BALLOU, R. H. The evolution and future of logistics and supply chain management. Revista Produção, v. 16, n. 3, p. 375, 2006.

BARDIN, L. Análise de conteúdo. Lisboa: Edições 70, 1977.

BLOEMHOF-RUWAARD, J. M.; VAN BEEK, P.; VAN WASSENHOVE, L. N. Interactions between operational research and environmental management. European Journal of Operational Research, v. 85, p. 229-243. Amsterdan, 1995.

BRITO, F. do V. et al. Estudo da Contaminação de Águas subterrâneas por BTEX oriundas de postos de distribuição no Brasil. In: Anais do $3^{\circ}$
Congresso Brasileiro de P\&D em Petróleo e Gás. IBP, Salvador, 2005.

CAJAZEIRA, J.; BARBIERI, J. Responsabilidade Social e Excelência Empresarial: Um Estudo com Empresas Ganhadoras do Prêmio Nacional da Qualidade. In: Anais eletrônicos do $30^{\circ}$ Enanpad. Brasília, 2006.

CERVO, A. L.; BERVIAN, P. A. Metodologia Científica. São Paulo: Prentice Hall, 2001.

COMPANHIA DE TECNOLOGIA DE SANEAMENTO AMBIENTAL. Perigos associados às substâncias químicas. Disponível em: <http://www.cetesb.sp.gov.br>. Acesso em 05 jan 2004

CHRISTOPHER, M. Distribuition, planning and control, a corporate approach. Hants: Gower, 1977.

CONSELHO NACIONAL DO MEIO AMBIENTE. Legislação. Disponível em: <http://www.mdic. gov.br $>$. Acesso em 20 ago 2008.

CORSEUIL, H. X.; MARINS, M. M. Contaminação de águas subterrâneas por derramamentos de gasolina: o problema é grave? Revista Engenharia Sanitária e Ambiental, v. 2, n. 2, p. 50-54. ABES: Rio de Janeiro, 1997.

DONAIRE, D. Gestão ambiental na empresa. São Paulo: Atlas, 1999.

DORNIER, P. P.; ERNEST, R.; FENDER, M.; KOUVELIS, P. Logística e Operações Globais: Textos e Casos. São Paulo: Atlas, 2000.
ELKINGTON, J. Towards the sustainable corporation: win-win-win business strategies for sustainable development. California Management Review. v. 36, n. 2, p. 90-100, 1994.

FAVERO, J.; MUNIZ, A. R.; SANTOS, R. P. B. Análise teórico-experimental da dispersão de poluentes líquidos em solos. Eng. Sanit. Ambient., v. 12, n. 4, p. 410-416, 2007.

FERREIRA, C. E. C. Acidentes com motoristas no transporte rodoviário de produtos perigosos. São Paulo em Perspectiva, v. 17, n. 2, p. 68-80. São Paulo, 2003.

FIGUEIREDO, R. Gargalos logísticos na distribuição de combustíveis brasileira. Instituto de Logística e Supply Chain - Artigos. Rio de Janeiro: maio, 2006. Disponível em <http:// www.ilos.com.br/index.php?option $=$ com docman\&task=cat_view\&gid=10\&ltemid=44>. Acesso em 15 ago 2008.

FLEURY, P. F.; WANKE, P.; FIGUEIREDO, K. F. Logística Empresarial: A Perspectiva Brasileira. São Paulo: Atlas, 2000.

GODOY, A. S. Introdução à pesquisa qualitativa e suas possibilidades. Revista de Administração de Empresas, v. 35, n. 2, p. 57-83, 1995.

GUIDE Jr., V. D. R. et al. Supply-Chain Managemant for recoverable manufacturing systems. Interfaces, v. 30, n. 3, p. 125-142, 2000

HARTMAN, C. L; JOFMAN, P. S.; STAFFORD, E. R. Partnerships: a path to sustainability. 
Business Strategy and the Environment, v. 8, p. 255-266, 1999.

KEEDI, S.; MENDONÇA, P. C. C. Transportes e Seguros no Comércio Exterior. 2. ed. São Paulo: Aduaneiras, 2000.

LAMBERT, D. M; COOPER, M. C. Issues in Supply Chain Management. Industrial Marketing Management, v. 29, n. 1, p. 65. New York, 2000.

LAMBERT, D. M; STOCK, J. R; VANTINE, J. G. Administração Estratégica da Logística. São Paulo: Vantine Consultoria, 1998.

LOUISOT, Jean-Paul. Finding one voice. Risk Management, v. 50, n. 4, p. 48-51. New York, 2003.

MALhOTRA, N. Pesquisa de Marketing. Porto Alegre: Bookman, 2001.
MASCARENHAS, F. A. B. A Proteção ambiental nas atividades de distribuição e revenda de combustíveis. Revista Pensar, v. 9, n. 9, p. 54-70. Fortaleza, 2004.

MULLER, E. J. The Greening of logistics. Distribuition, v. 90, n. 1, p. 26-30. 1991.

RODRIGUEZ, M. A.; RICART, J. E.; SANCHEZ, P. Sustainable Development and the sustainability of competitive advantage: a dynamic and sustainable vies of the firm. Creativity and Innovation Management, v. 11, n. 3, p. 135-146, 2002.

ROSSI, M. S.; BROWN, H. S.; BAAS, L. W. Leaders in sustainable development: How agents of change define the agenda. Business Strategy and the Environment Bus, v. 9, p. 273286, 2000.

SANDELANDS, E. Dirty, hard and dangerous. International Journal of Physical Distribuition \& Logistics Management, v. 24, n. 3, p. 7-8. Bradford, 1994.
TAN, K. C. A framework of supply chain management literature. European Journal of Purchasing \& Supply Management, v. 7, p. 39, 2000.

TRISTÃO, J. A. M. et al. Gestão Ambiental de Resíduos de Óleos Lubrificantes: o Processo de Rerrefino. In: Anais eletrônicos 29ํㅡㄹ Enanpad. Salvador, 2005.

VELEVA, V. et al. Indicators for measuring environmental sustainability: A case study of the pharmaceutical industry. Benchmarking, v. 10, p. 107-119. Bradford, 2003.

VIANA, J. J. Administração de Materiais. São Paulo: Atlas, 2000

WELSH, C. N.; HERREMANS, I. M. Tread softly: adopting environmental management in the start-up phase. Journal of Organizational Change Mangement, v. 11, n. 2, p. 145-155. Bradford, 1998.

\section{SOBRE OS AUTORES}

\section{Mauricio Henrique Benedetti}

Universidade Presbiteriana Mackenzie / Universidade Federal de São Carlos

Rua da Consolação, 930 - 01302-907

Tel.: (11) 2114-8802 (com.)

E-mail:mhbenedetti@uol.com.br

\section{Patricia Lima}

Universidade Presbiteriana Mackenzie

E-mail: tri_lima@yahoo.com.br

\section{Luana Melatto}

Universidade Presbiteriana Mackenzie

E-mail: luana.melatto@hp.com

\section{Marcos Silva}

Universidade Presbiteriana Mackenzie

E-mail:marcos.silva@thomasgreg.com.br 